\title{
Economia Solidária e a dimensão cognitiva da experiência dos catadores
}

\author{
Solidarity Economy and the cognitive dimension of the collectors' experience
}

\section{Economía Solidaria y la dimensión cognitiva de la experiencia de los recolectores}

\author{
Jean Carlos Machado Alves ${ }^{1}$ \\ Letícia Helena Medeiros Veloso² \\ Emmanuel Paiva de Andrade ${ }^{2}$ \\ Andreia Maria da Silva ${ }^{3}$
}

Recebido em 23/10/2018; revisado e aprovado em 17/04/2018; aceito em 30/04/2019.

DOI: http://dx.doi.org/10.20435/inter.v21i1.2199

\begin{abstract}
Resumo: O objetivo do artigo é refletir sobre as possibilidades e os desafios de uma "outra economia", representada pela chamada Economia Solidária, a partir da descrição das experiências de associações de catadores de materiais recicláveis vinculadas a uma rede de catadores em Minas Gerais. O artigo se baseia em pesquisa qualitativa, alguns conceitos, dados relativos às atividades diárias das associações. Concluímos sugerindo que, embora os desafios, entraves e a sujeição quase inevitável à lógica capitalista continue dando as cartas no jogo social, existe potencial, a partir dessas formas de organização, para alguma emancipação e enfrentamento das forças mais profundas que regulam a sociedade capitalista e mantêm a taxa de exploração em níveis insuportáveis.
\end{abstract}

Palavras-chave: Economia Solidária; catadores; associativismo.

Abstract: The objective of this article is to reflect on the possibilities and challenges of an "other economy", represented by the so-called "Solidarity Economics", based on the description of the experiences of associations of recyclable waste collectors linked to a network of collectors in Minas Gerais. The article is based on qualitative research, some concepts, data related to the daily activities of associations. We conclude by suggesting that although the challenges, obstacles and almost inevitable subjection to capitalist logic continue to play a role in the social game, there is potential from these forms of organization for some emancipation and confrontation of the deeper forces that regulate capitalist society and keeps the rate of exploitation unbearable.

Keywords: Solidarity Economy; waster collectors; associativism.

Resumen: El objetivo del artículo es reflexionar sobre las posibilidades y los desafíos de una "otra economía", representada por la llamada "Economía Solidaria", a partir de la descripción de las experiencias de asociaciones de recolectores de materiales reciclables vinculadas a una red de recolectores en Minas Gerais. El artículo se basa en la investigación cualitativa, algunos conceptos, datos relativos a las actividades diarias de las asociaciones. Concluimos sugiriendo que, aunque los desafíos, obstáculos y la sujeción casi inevitable a la lógica capitalista continúan dando las cartas en el juego social, existe potencial, a partir de esas formas de organización, para alguna emancipación y enfrentamiento de las fuerzas más profundas que regulan la sociedad capitalista y mantienen la tasa de explotación en niveles insoportables.

Palabras clave: Economía Solidaria; recolectores de materiales reciclables; asociativismo.

\section{INTRODUÇÃO}

Este artigo trata de um tema que, em certo sentido, ainda aparece relativamente pouco nos estudos mais gerais sobre movimentos sociais e sobre associativismo: os modos de organização e associação dos chamados "catadores de materiais recicláveis", ou seja, pessoas que extraem seu sustento daquilo que o restante da sociedade entende como "lixo". Pouco se sabe sobre estas pessoas, mas sabe-se menos ainda sobre como elas se articulam em associações e movimentos sociais pautados pelas lógicas da chamada Economia Solidária.

\footnotetext{
${ }^{1}$ Universidade Federal de Ouro Preto (UFOP), Ouro Preto, Minas Gerais, Brasil.

${ }^{2}$ Universidade Federal Fluminense (UFF), Niterói, Rio de Janeiro, Brasil.

${ }^{3}$ Comissão Nacional de Energia Nuclear/Instituto de Engenharia Nuclear (CNEN/IEN), Rio de Janeiro, Brasil.
} 
Magalhães, Alves e Veloso (2016) e Cunha e Santos (2011) utilizam o termo Economia Solidária para se referir àquelas formas de organização produtiva e do trabalho que se pautam por valores como solidariedade, cooperação e autogestão, em contraposição a valores como lucro, competição e livre-mercado. Alguns autores (CUNHA; SANTOS, 2011) consideram estar em construção, aqui, uma "outra economia", que, ao questionar os modos hegemônicos de produção e consumo, busca oferecer aos participantes novas formas de acesso a trabalho e cidadania.

Ao enfocar uma rede de associações de catadores de materiais recicláveis, nosso objetivo neste artigo é tanto descrever essas associações e suas formas de fazer Economia Solidária quanto apontar alguns dos principais problemas enfrentados por tais associações e que parecem frear a própria possibilidade de emancipação prometida por essa "outra economia". Mais especificamente, o foco do artigo é uma rede de associações situada na região do Vale do Aço, Rio Doce e Mucuri, em Minas Gerais, composta por 12 associações de catadores de materiais recicláveis - somando 169 catadores -, todas integrantes do Movimento Nacional dos Catadores de Materiais Recicláveis (MNCR). As associações realizam atividades de coleta, triagem e venda de materiais recicláveis, enquanto a rede tem por objetivo comercializar esses materiais. Para proteger as identidades dos envolvidos, chamaremos, aqui, a rede de ABC.

Tomando como base pesquisa empírica qualitativa realizada em seis dessas associações, ao longo do segundo semestre de 2016 e do primeiro semestre de 2017, discutimos abaixo seus modos de organização e alguns dos principais desafios que encontram cotidianamente. Iniciamos a discussão com alguns breves comentários contextualizadores sobre capitalismo, Economia Solidária e associativismo; estendemos a reflexão, a seguir, para tratar de alguns dos principais limites e possibilidades inerentes à atividade da "catação", bem como do MNCR como uma forma de se contrapor a essas limitações; e, em seguida, discutimos as experiências, dificuldades e avanços que a pesquisa pôde perceber na atuação dessas seis associações. Concluímos sugerindo que, embora os desafios, entraves e a sujeição quase inevitável à lógica capitalista continue dando as cartas no jogo social, existe potencial, a partir dessas formas de organização, para emancipação e enfrentamento das forças mais profundas que regulam a sociedade capitalista e mantêm a taxa de exploração em níveis insuportáveis.

\section{CAPITALISMO, ECONOMIA SOLIDÁRIA E ASSOCIATIVISMO}

A história do capitalismo, desde a superação do feudalismo até hoje, é uma sequência de transformações que, se de um lado supera ou sufoca os tensionamentos produzidos por ele mesmo, por outro lado, predominantemente, acelera a taxa de exploração dos trabalhadores e aumenta a taxa de lucro dos capitalistas (BOLTANSKI; CHIAPELLO, 2009; HARVEY, 2011; HOBSBAWM, 1987). Esse processo vai desde a mercantilização dos recursos naturais, do trabalho e das relações sociais, até a captura e subordinação das formas de produção do conhecimento, com a introdução de novos modos de produzi-lo dentro do que alguns autores chamam de "necessidades cognitivas" do capitalismo:

Desde o século XVII, nos principais centros hegemónicos desse padrão mundial de poder [...] desse universo intersubjetivo, foi elaborado e formalizado um modo de produzir conhecimento que dava conta das necessidades cognitivas do capitalismo: a medição, a externalização (ou objetivação) do cognoscível em relação ao conhecedor, para o controle das relações dos indivíduos com a natureza e entre aquelas em relação a esta, em especial a 
propriedade dos recursos de produção. Dentro dessa mesma orientação foram também, já formalmente, naturalizadas as experiências, identidades e relações históricas da colonialidade e da distribuição geocultural do poder capitalista mundial. (QUIJANO, 2010, p. 74).

Dando sequência ao argumento, Quijano (2010) vai afirmar que essa "colonialidade" é marca registrada do capitalismo; ela se manifesta e manifestou, tanto há 500 anos quanto hoje, por exemplo, pela sujeição do trabalho humano (salariado, mercantil, mas por vezes também servil e escravo) ao capital. O que, em última análise, significa, comumente, a desumanização dos atores que exercem tal trabalho, pelo fato mesmo de estarem sujeitos a esta lógica que Quijano (2010) denomina de "colonialidade". Santos (2010, p. 31), por sua vez, reforça "que esta realidade é tão verdadeira hoje como era no período colonial. O pensamento moderno ocidental continua a operar mediante linhas abissais que dividem o mundo humano do sub-humano, de tal forma que princípios de humanidade são postos em causa por práticas desumanas".

Entre tais "práticas desumanas", no seio de tal lógica da "colonialidade", apontam esses autores para o fato de que, no capitalismo, tem-se, conjuntamente à exploração do trabalho e à desumanização dos trabalhadores, uma colonização dos saberes e conhecimentos, segundo a qual só alguns são válidos e legítimos, enquanto outros são rejeitados como menos válidos. Estaríamos aqui falando, por exemplo, daqueles membros das camadas mais inferiores da sociedade, que teriam tanto sua força de trabalho quanto seus saberes particulares desvalorizados pelos saberes hegemônicos. E, no entanto, tais pessoas ainda constroem e habitam espaços coletivos que, também, são produtores de saberes e, por sua vez, não necessariamente seguem os requisitos do saber hegemônico; são saberes que operam "não como algo cognitivo exclusivamente, mas envolvendo visões de mundo, percepções e representações que abrangem a vida psíquica e a produção simbólica desses sujeitos, suas expressões identitárias e socioculturais" (VERONESE, 2016, p. 214). E ainda:

[...] toda a experiência social produz e reproduz conhecimento e pressupõe uma epistemologia, definida como um modo de conceber as coisas e os pressupostos sobre o que consiste em conhecimento válido. Não há, pois, conhecimento sem práticas e sem atores sociais engajados em produzi-las. Interessam-nos os saberes produzidos por esses grupos de pessoas consideradas "inferiores" na lógica hegemônica de hierarquização do conhecimento e do reconhecimento social. (VERONESE, 2016, p. 214-5).

Tal "injustiça cognitiva", ou seja, a não valorização de outros saberes e práticas que não os hegemonicamente aceitos pelo capitalismo, tende a aparecer claramente quando se pensa em populações e grupos marginalizados, como as populações de rua (de onde advêm muitos dos catadores de materiais recicláveis), as quais, também fruto dos crescentes índices de desemprego, como colocam Jacobi e Teixeira (1997, p. 6), são compostas "principalmente daqueles que foram excluídos do mercado de trabalho e afetados por uma situação de miséria absoluta que tem afligido uma parte considerável de cidadãos".

Esta miséria, no entanto, não consegue impor a total exclusão de lógicas sociais como as do conhecimento, da organização social e do associativismo. Ao contrário do que sugere o senso comum, os saberes produzidos e os espaços vivenciados por atores sociais como as populações de rua e os catadores de materiais recicláveis são plurais, indo desde interações com a sociedade civil no seu sentido mais amplo (como os movimentos sociais), até as formas de organização mais restritas e locais, como associações e cooperativas. Os saberes que neles circulam - como trabalhar, como se organizar, como orientar a ação para o bem comum - são igualmente múl- 
tiplos e sempre criativos. Todos esses espaços, e os sujeitos que os habitam, são produtores de relações sociais em níveis e formas diversificadas, gerando novos conhecimentos e saberes, os quais, porém, nem sempre são valorizados pelo senso comum da lógica capitalista.

Esta lógica tende a ver o catador como um sujeito inferior, sem conhecimento formal e ou técnico, ou seja, aceitável pelo estado dominante do capitalista, reproduzindo ações vinculadas aos pensamentos da colonização econômica, gerando aquilo que podemos chamar de "injustiça cognitiva". Assim, refletir sobre a descolonização da economia necessita admitir que, para que se tenha justiça social, é necessário justiça cognitiva global. A busca, portanto, do tratamento equitativo de todos os saberes reforça a necessidade de visibilidade das outras formas de conhecimento, principalmente dos saberes marginalizados (MENESES, 2009).

Fernandes e Pires (2016) sugerem que o recrudescimento das desigualdades socioeconômicas das últimas décadas reflete uma sociedade incapaz de inserir indivíduos aptos a trabalhar. Mas, ao mesmo tempo, dizem eles, é exatamente no âmbito dessa crise que surgem iniciativas coletivas baseadas na autogestão, no cooperativismo, no associativismo e na Economia Solidária.

De uma maneira um tanto quanto esquemática, podemos dizer que parte das discussões sobre economia solidária diz respeito ao sentido que esse termo possui em relação às transformações pelas quais passaram as sociedades capitalistas nas últimas décadas. [...] Nesse enquadramento, importância é conferida à potência que essa forma de organização social possui em termos da transformação das relações de produção capitalistas, uma vez que são experiências em que há apropriação coletiva dos meios de produção. (FERNANDES; PIRES, 2016, p. 185)

A questão do conhecimento produzido na Economia Solidária é importante por apontar para formas diferentes (da lógica hegemônica capitalista) de agir, pensar, produzir e comercializar que vêm sendo alavancadas por essas "outras economias" - como é o caso da Economia Solidária. Neste sentido, insistem Santos, Hespanha e Santos (2011, p. 12), "as novas abordagens epistemológicas e metodológicas das pesquisas sobre economia solidária têm de ser capazes de reconhecer os aspectos invisibilizados ou negligenciados pelo saber convencional [...] dos modos de participação social e política, da racionalidade alternativa dos empreendimentos [...]".

Autores como Magni e Gunther (2014) e Barros e Pinto (2008) sugerem que a participação em movimentos associativos, fundamental à noção de Economia Solidária, proporciona uma identificação política e gera sociabilidades embasadas na solidariedade em torno de um objetivo comum, o da contraposição aos meios de exploração, opressão e individualismo que permeiam os cotidianos. É em parte para contrapor tais situações que os sujeitos se organizam em associações e ou cooperativas solidárias. Pode-se mesmo dizer que, de acordo com a perspectiva de interações econômicas proposta por Polanyi (2012), ou seja, a interação entre domesticidade, reciprocidade, redistribuição e mercado, os empreendimentos econômicos ditos "solidários" apresentam formas híbridas que convergem e dialogam com as várias formas mais hegemônicas da economia, combinando, por assim dizer, o econômico ao social. Por meio destas interações, sugerimos que, ao se associarem e organizarem, grupos formados por pessoas marginalizadas (como é o caso dos catadores de materiais recicláveis) engendram, na união e no trabalho associativo, cooperativo e "solidário", suas lutas sociais, políticas e econômicas. 


\section{O MOVIMENTO NACIONAL DOS CATADORES DE MATERIAIS RECICLÁVEIS: LIMITES E POSSIBILIDADES}

No final da década de 80, teve início, em Belo Horizonte, uma ação promovida pela Pastoral de Rua com alguns movimentos sociais, os quais começaram a pesquisar e conhecer melhor 0 perfil da população de rua desse município. A partir daí, e levando em consideração os diferentes perfis de pessoas marginalizadas detectados, a Pastoral e os movimentos sociais elaboraram estratégias visando amenizar ou melhorar a situação socioeconômica dessa população. Ao mesmo tempo, pessoas que viviam nas ruas já estavam buscando alternativas que lhes proporcionassem alguma renda. Muitos já exerciam atividades de catação de materiais recicláveis e foram principalmente esses os que iniciaram a organização coletiva por meio de associações e cooperativas (MAGNI; GUTHER, 2014).

Esse tipo de iniciativa foi se multiplicando e, em 1999, a partir do 1 o Encontro Nacional de Catadores de Papel, surgiu a ideia de se organizarem num verdadeiro movimento social. Nascia, assim, em 2001, o Movimento Nacional dos Catadores de Materiais Recicláveis (MNCR), no seio do 1 o Congresso Nacional dos Catadores de Materiais Recicláveis, do qual participaram cerca de 1.700 catadores.

Na sequência, em 2003, aconteceu o 1으 Congresso Latino-Americano de Catadores, o qual propôs uma carta em que denunciava a situação dos catadores da América Latina. Em 2005, aconteceu o 2 o Congresso Latino-Americano dos Catadores, que deu continuidade às lutas pelos direitos dos catadores latinos. Em relato do próprio Movimento,

Com o surgimento do MNCR ampliou-se a luta dos catadores(as) por uma vida digna. Nossa categoria é historicamente excluída da sociedade e muitos catadores(as) ainda sobrevivem de forma precária em lixões e nas ruas. O trabalho de coleta de materiais recicláveis significa garantir alimentação, moradia e condições mínimas de sobrevivência para uma parcela significativa de nosso povo brasileiro. Apesar das imensas dificuldades, resistimos e lutamos dia a dia pela vida. Pelo direito de trabalhar honestamente e sobreviver. (MNCR, 2008).

Para Silva (2006, p. 4), o MNCR deve ser entendido como um espaço de relações e diálogo entre atores, governo e políticas públicas, a partir de um cenário complexo, cuja ação transforme e empodere os sujeitos sociais envolvidos, "ressignificando e atualizando sua função social, reafirmando-se e ocupando novos espaços, ou mesmo atuando como responsáveis por criar ou modificar institucionalmente as 'regras do jogo'". Trata-se de um movimento que se baseia na luta pela participação direta e efetiva do trabalhador, visando, por um lado, a ressignificação da "catação" como "trabalho" efetivo, sujeito a direitos e organização social, de forma a modificar as percepções estigmatizantes de que os catadores são alvos, e, por outro lado, a potencialização de formas de acesso e inclusão através da garantia de renda e sustento.

Entre as ações que desenvolvem, no âmbito do MNCR, os catadores, além de lutar pelo reconhecimento de sua atividade laboral como "trabalho", também desenvolvem uma série de projetos educacionais, culturais e recreativos para si próprios e seus familiares. Uma de suas principais bandeiras tem sido o resgate do papel das mulheres catadoras, que são maioria nas associações e cooperativas. Para tanto, desenvolvem-se atividades específicas para facilitar a formação profissional e educacional das catadoras e sua participação e luta no movimento. Busca-se, ainda, construir parcerias com entidades públicas e privadas não só para garantia de trabalho, mas também educação e saúde. 
Outro ponto importante é sua luta pela implantação da coleta seletiva solidária, através de projetos de educação socioambiental nas comunidades onde estão inseridos, discutindo questões como o valor social dos resíduos (do "lixo"), o desenvolvimento sustentável, a saúde pública etc. Nessa perspectiva, buscam também combater os lixões, espaços degradantes onde alguns catadores ainda trabalham e que os expõem a riscos de saúde dos mais graves. Finalmente, lutam ainda pela inclusão social dos catadores a partir da remuneração pelos serviços ambientais por eles realizados, tais como a coleta solidária, a triagem e destinação adequada dos resíduos etc., remuneração esta que, ao ver deles, deveria ser realizada pelas prefeituras, para as quais estariam prestando um serviço de utilidade pública.

Esta perspectiva vem ao encontro do que preceitua a Lei 12.305/2010, referente à Política Nacional de Resíduos Sólidos, ao incentivar a criação e o desenvolvimento de cooperativas e associações de catadores, postulando-os como agentes principais da coleta seletiva, da eliminação dos lixões e da disposição adequada dos resíduos sólidos no Brasil (BRASIL, 2010). As lutas por reconhecimento (e remuneração) também estão em sintonia com o reconhecimento, em 2002, pelo Ministério do Trabalho, da profissão de catador, a qual recebeu o número 5192 na Classificação Brasileira de Ocupações (CBO).

Em que pese à relevância do MNCR no horizonte de organização e luta dos catadores, os desafios enfrentados são muitos e variados. Há uma dimensão cultural na consolidação do trabalho da categoria que é fortemente dependente de uma educação ambiental que incentive a população no cuidado com a separação e disposição dos seus rejeitos. Também os catadores, pressionados por prazos e metas, não conseguem fazer coleta e triagem de maneira adequada, separando os materiais da forma correta, por exemplo. Há também a falta de infraestrutura e logística, pois faltam depósitos e instalações adequadas para separar, limpar e organizar os resíduos coletados. E há o problema do transporte dos materiais triados, os quais precisam ser levados aos centros de venda e indústria de reciclagem.

Além disso, nem sempre há disponibilidade de recursos financeiros para pagamentos, por exemplo, de frete ou motoristas para levarem as cargas. Há de se enfrentar, também, questões em nível da própria gestão de pessoas, como a rotatividade e o absenteísmo entre os catadores, as doenças e demais problemas de saúde por eles enfrentados, indo até a dependência química, como resultado das condições sociais e de trabalho dos catadores. Tudo isso tem consequências para a atividade como um todo, bem como para as possibilidades de associação e organização, implicando em necessidade constante de capacitação, seja no âmbito pessoal, seja na esfera da gestão das próprias cooperativas.

Podem-se indicar quatro razões que provocam elevada rotatividade: 1) dificuldades de adaptação de algumas pessoas às práticas cooperativistas, visto que vários catadores vêm das ruas com vícios no desempenho de sua profissão; 2) problemas de relacionamento entre os membros, decorrentes da fragilidade organizacional; 3) instabilidade da renda e 4) visão dos membros de que não se trata de uma atividade permanente e que a possibilidade de emprego formal é sempre mais atraente. Os que ficam querem o apoio da organização e o reconhecimento da sociedade, para que não sejam mais vistos como marginais. (BUQUE; RIBEIRO, 2015, p. 305).

Em face de um quadro tão ampliado de limites e possibilidades, as respostas são, fundamentalmente, construídas a partir de experiências locais que aportam uma variedade de caminhos próprios, de lideranças forjadas na própria luta pela existência e de uma cultura política 
e social capaz de incentivar ou frear os experimentos. É, portanto, com esse olhar atento às especificidades locais que passamos a discutir a experiência da rede de catadores em questão.

\section{EXPERIÊNCIAS EM UMA REDE DE ASSOCIAÇÕES DE CATADORES}

A pesquisa que fundamenta este trabalho foi de natureza qualitativa, priorizando a observação participante, possibilitada por meio da convivência com os sujeitos pesquisados, construída ao longo do segundo semestre de 2016 e o primeiro de 2017. Foram pesquisadas seis associações de catadores, em seis municípios diferentes de Minas Gerais ${ }^{4}$, que pertencem à Rede ABC. Participaram do estudo todos os membros das associações, incluindo as lideranças, presidentes e associados, o que implicou na realização de diálogo com os catadores durante suas atividades laborais em seus locais de trabalho.

Os encontros foram realizados coletivamente a partir da interação e vivência das atividades dos catadores. As conversas eram, na maior parte das vezes, informais, procurando o pesquisador tornar-se o mais "invisível" possível, seja adequando-se convenientemente com relação ao vestuário, ao modo de falar e aos instrumentos da coleta, seja incentivando ao espaço de fala todos os participantes. A partir das falas, novos questionamentos surgiam, trazendo questões de interesse da pesquisa e contribuindo para a construção de relação de confiança, de falas mais verdadeiras e de naturalidade nas posturas dos catadores.

Os grupos estudados são das cidades de Teófilo Otoni, Governador Valadares, Belo Oriente, Cachoeira Escura, Coronel Fabriciano e João Monlevade. A limitação a seis associações em vez das 12 que compõem a rede se deu ao fato de que, em contato preliminar com lideranças da rede $A B C$, os contatos telefônicos e endereços de e-mail de todas as associações nos foram repassados; embora tenhamos feito contato com todas, só seis responderam ${ }^{5}$.

Um fato relevante durante a pesquisa foi a reunião ocorrida em 2016 em João Monlevade com representantes da maioria das associações vinculadas à rede. O objetivo da reunião foi aprovar a formalização da Rede ABC, bem como seu estatuto, em que constam explicitamente os mesmos ideais de cooperação, solidariedade ou autogestão preconizados pela noção de Economia Solidária. Entendemos este posicionamento como um alinhamento significativo da nova rede que ali se formalizava com o que aqui temos chamado de uma nova forma de se fazer economia.

Limitações empíricas de ordem técnica, econômica e social, no entanto, tais como as financeiras ou de logística, qualificação de pessoal, entre outras, aliadas à variedade de concepções acerca do papel e da função de uma rede, distanciam o ideal da nova economia da sua prática efetiva. Enquanto boa parte das lideranças valorizava o papel da rede como um mecanismo de estruturação permanente dos dispositivos de poder, para os catadores, a Rede ABC deveria ser tão somente um instrumento para a comercialização.

Nessa perspectiva, a rede só se tornaria útil na medida em que permitisse o acesso às empresas que são potenciais compradoras dos materiais catados. Para as lideranças, a rede muitas vezes se manifesta mais como forma de reprodução de posições de poder do que como mecanismo de inclusão e participação concreta dos catadores, suas práticas e seus saberes.

\footnotetext{
${ }^{4}$ Para preservar nossos entrevistados, modificaram-se os nomes das associações, mantendo o nome original dos municípios onde se realizou a pesquisa.

${ }^{5}$ Pareceu-nos que os contatos para os quais não obtivemos resposta estavam desatualizados, mas não conseguimos confirmar este fato.
} 
Além disso, embora constituam oficialmente uma rede, há diferenças profundas nos modos de trabalho das associações.

Assim, um ponto importante a ressaltar é que, embora a ideia de "rede", bem como a de um "movimento social" (como o MNCR, que consubstancia a Rede ABC), como a de "associativismo", enfatize noções de cooperação, compartilhamento de informações e ação conjunta, na prática observamos que o fluxo de informações dentro da Rede $A B C$ se limita às lideranças das associações que compõem a rede e que essas lideranças relutam em repassar tais informações aos demais membros, mesmo àqueles internos às suas próprias associações. Informações como quem são os parceiros com os quais se faz negócios, por exemplo, ou quem são os financiadores desta ou daquela atividade, que seriam importantes de serem compartilhadas entre todos os membros, não são repassadas pelas lideranças àqueles a quem lideram.

Um exemplo é que as lideranças da Rede ABC afirmam ter como parceiro o Centro Mineiro de Referência em Resíduos, importante órgão público que em muito Ihes poderia auxiliar, tanto no trabalho propriamente dito dos catadores quanto em sua formação e articulação social: considerando o grau de tecnologia, conhecimento e informação produzido e catalogado por esse centro, poder-se-ia estabelecer frutífera parceria, via compartilhamento de informações, entre o centro e o MNCR (do qual todas as associações são associadas). Por exemplo, os catadores poderiam ter acesso, via o centro, a novas tecnologias de separação e descontaminação de resíduos, tecnologias estas que poderiam utilizar em sua prática cotidiana, enquanto o centro poderia obter informações mais completas sobre o cotidiano do trabalho de catador, os desafios encontrados e quais dentre eles se deve priorizar na busca de melhorias (SILVA, 2006).

Na prática, porém, não é o que acontece: as discussões entre lideranças e o centro não chegam até os catadores, as estratégias propostas não levam em conta as necessidades destes, e muito desse conhecimento se perde. Percebe-se, também, seja como causa, seja como consequência dessa centralização de informações, certo desinteresse da parte dos associados, que repetidamente faltam às reuniões ou deixam de incorporar as informações ali discutidas em suas práticas diárias.

Observa-se, ainda, que os catadores tendem a priorizar aquelas atividades que atendem a suas necessidades materiais mais básicas e imediatas, como a coleta de materiais apenas no montante equivalente ao valor de troca suficiente para lhes garantir o sustento em determinado mês. Esta ênfase no imediato, por sua vez, impede que tanto catadores quanto seus representantes e lideranças atentem para outras necessidades igualmente prementes, mas não imediatas dos catadores, como os riscos à saúde que tal atividade envolve e os problemas de saúde que eles já experimentam em decorrência de seu trabalho (BUQUE; RIBEIRO, 2015).

Outra questão se refere ao estabelecimento de parcerias entre prefeituras e associações de catadores. A Lei n. 12.305/2010, referente à Política Nacional de Resíduos Sólidos, prevê exatamente, como uma das formas de enfrentamento de problemas ambientais, sociais e econômicos, as seguintes ações: eliminação dos lixões, diminuição na geração de resíduos e implantação da coleta seletiva, priorizando os catadores nesse processo (BRASIL, 2010). Porém, mesmo nos (poucos) casos em que prefeituras realmente estabeleceram parcerias com associações de catadores, em atendimento à Lei, não se trata verdadeiramente de "parcerias" com base em valores de cooperação e associativismo, pois os catadores continuam subvalorizados e deles são exigidos resultados e metas mais alinhados a uma perspectiva capitalista tradicional de exploração do trabalho (BOLTANSKI; CHIAPELLO, 2009; HARVEY, 2011; HOBSBAWM, 1987). 
Passando agora para cada associação em particular, o local onde a associação de catadores de Teófilo Otoni se localiza é particularmente problemático, pois, embora situado na região central da cidade e dispondo de espaço amplo, apresenta uma infraestrutura precária e vulnerável a inundações. Além disso, apesar de a associação atualmente ser composta por apenas sete catadores, ela apresenta problemas internos e divisões profundas que dificultam o trabalho associativo: os associados enfrentam dificuldades de comunicação interpessoal e de diálogo, o que por vezes inviabiliza a tomada de decisões, também em parte porque os catadores não são ouvidos pela liderança interna a esta associação. Além disso, os próprios associados não têm por hábito se reunir para discutir questões da associação, pois seu único foco é produzir. Mesmo essa produção é prejudicada, porém, pelo fato de que os materiais coletados ainda não estão sendo comercializados através da Rede $A B C$, e sim autonomamente; como a produção é pequena, não gera os recursos necessários para que se pague o frete até João Monlevade, que é a sede da rede e onde se centralizam todas as atividades de comercialização.

A associação tem algumas parcerias com entidades públicas e privadas que atuam de forma mais pontual com doações de resíduos ou assessorias sociotécnicas. Observou-se que os catadores têm a cultura de transferir responsabilidades a terceiros; por exemplo, o controle financeiro a um contador que faz serviço voluntário junto ao empreendimento. Eles acreditam que esse parceiro, por ter uma formação técnica e superior, estaria mais apto em administrar as finanças (SANTOS, 2010).

Outro problema é que o município não tem coleta seletiva nem, por conta disso - ao menos dentro do que pudemos observar durante a pesquisa -, nenhuma relação formal ou informal com o poder público. Não havendo coleta seletiva na cidade, os catadores ou recebem doações informais de resíduos na sede da associação ou se deslocam pela cidade portando carrinhos de tração humana em sua busca por materiais recicláveis; esta atividade em si mesma lhes impõe não só dificuldades físicas, como incentivos negativos ao trabalho da "catação", uma vez que o retorno por um dia de trabalho tende a ser pífio.

Segundo alguns catadores dessa associação, certos problemas poderiam ser evitados ou amenizados, caso a liderança da associação realmente se importasse com seu bem-estar e com a construção de articulações políticas locais (com o poder público) que lhes permitissem pleitear tais facilitadores. Isto não acontece, segundo eles, porque, embora a liderança seja bem conectada social e politicamente, só utiliza este capital social em proveito próprio, e não do coletivo.

Passando para a próxima associação, em Governador Valadares, o grupo é formado por 48 associados que, porém, não são catadores realizando coletas: essas são realizadas, conforme acordo com a prefeitura, por uma empresa terceirizada, contratada e paga pelo município, a qual transporta os materiais coletados para a associação. Mesmo com este suposto benefício oriundo de uma parceria com ao poder público, obtido graças às lutas do MNCR e seus membros, os associados manuseiam os resíduos recebidos, estando, assim, sujeitos a riscos de contaminação e demais problemas de saúde, agravados pelo fato de que poucos deles utilizam equipamentos de proteção individual, ficando, desta forma, expostos a toda sorte de riscos ambientais (lembrando que a cidade até hoje sofre os efeitos resultantes do rompimento da barragem de resíduos de minério do distrito de Mariana). Além disso, o que parece um benefício - o contrato com a prefeitura - está em vias de ser revisto desde a mudança na gestão municipal, em 2017: a nova prefeitura pretende propor um novo contrato, segundo o qual novas exigências serão feitas aos associados da organização, como o pagamento da previdência social pelos próprios associados. 
O ambiente de trabalho dos catadores, como o galpão, foi reformado e ampliado, mas eles reclamaram da forma como se deu o processo de desenvolvimento do projeto da construção de partes do galpão, pois eles foram completamente ignorados ao conversarem com os profissionais técnicos responsáveis, como os engenheiros, para dar sugestões sobre as particularidades de sua atividade e necessidade no ambiente de trabalho. Assim, a construção da rampa, por exemplo, atende parcialmente as atividades dos catadores (VERONESE, 2016; MENESES, 2009).

Ainda outro problema relatado pelos associados era de que a prefeitura, repentinamente, deixou de transportar os resíduos para o aterro no interior da associação, depositando-o, em vez disso, num lixão a céu aberto localizado ao lado da sede da associação. Um problema cotidiano e bem prático é que, para este lixão, convergem várias outras pessoas que buscam ali seu sustento; quando com sede, estas mesmas pessoas vêm à sede da associação beber água, sem as devidas precauções, o que aumenta o risco de contaminação para todos.

Em um tom mais positivo, os associados ali nos informaram que apreciam o trabalho na associação pela autonomia e flexibilidade, bem como pela possibilidade de diálogo entre seus pares, uma vez que ali, diferentemente da associação anterior, é comum os associados se reunirem para conversar e deliberar sobre a associação (MAGALHÃES; ALVES; VELOSO, 2016; CUNHA; SANTOS, 2011).

Quanto à comercialização dos materiais através da Rede $A B C$, embora aqui também não existisse esta opção, os motivos eram diferentes dos da associação anterior: esses associados consideram que têm conseguido o mesmo preço, comercializando seu material individualmente, do que conseguiriam via rede; fazer parte da rede lhes era, neste sentido, indiferente.

A terceira associação que pesquisamos se localiza no distrito industrial de Coronel Fabriciano; seu aluguel, bem como as despesas com água, luz, telefone e o motorista do caminhão para transportar os resíduos, eram custeados pela prefeitura. Aqui, os catadores não coletam seus materiais nas ruas puxando carrinhos de tração humana; trabalha-se somente com materiais recolhidos pelo caminhão e com doações de organizações que deixam seus resíduos na associação. Este grupo é composto, em sua maioria, por mulheres idosas que não têm por hábito conversar regularmente sobre as necessidades da associação: elas tendem a reagir a problemas quando estes aparecem, em vez de buscar uma postura mais proativa de discussão, debate e deliberação.

Esse coletivo apresenta vários problemas de relacionamento interpessoal e organização interna e externa que, de alguma forma, eram amenizados por profissionais funcionários da prefeitura que atuavam junto à associação, exercendo atividades mais técnicas e administrativas, o que pode gerar dependência e dificuldade de desenvolvimento de novos conhecimentos e empoderamento dos catadores (VERONESE, 2016; MENESES, 2009).

Mesmo trabalhando sob condições adversas, as catadoras nesta associação prezam pela organização e limpeza do galpão onde se acumulam os materiais coletados para posterior comercialização. Apesar da poeira e da grande quantidade de materiais acumulados (vidro, latas, papel), há um cuidado no manuseio e armazenamento destes, orgulhando-se as associadas desta característica.

Por outro lado, essa capacidade de se organizar não necessariamente se transpõe para a atividade de coleta e comercialização em si: as associadas perderam, recentemente, vários parceiros que lhes doavam materiais, por dois motivos: as associadas não conseguiam cumprir os prazos estabelecidos para a entrega, que segundo elas dependia do caminhão da prefeitura, 
que nem sempre estava disponível, e não conseguiam se planejar com antecedência suficiente para atender às demandas. Como resultado, também esta associação não está comercializando seus materiais via a Rede $A B C$, porque o montante que conseguem coletar não lhes garante recursos financeiros suficientes para pagar o frete do transporte dos materiais até a central em João Monlevade.

Já da associação em Belo Oriente fazem parte quatro associados e, em Cachoeira Escura, seis associados; ambos, município e distrito, integram a associação. Também essas localidades foram fortemente afetadas pelo rompimento da barragem de resíduos de minérios de Mariana, que gerou diversos impactos na cidade e região. Ainda na época da pesquisa, alguns associados relatavam problemas de falta de água no galpão da associação, embora este fosse alugado e pago pela prefeitura. Não há ali coleta seletiva, mas recentemente essa associação (e a prefeitura) foram contempladas com um projeto da Fundação Banco do Brasil para a implantação da coleta seletiva, a partir da construção de um galpão, e para aquisição de um caminhão.

Neste contexto, o poder público local parecia se limitar apenas a atender às demandas e exigências técnicas e administrativas desse projeto. Novamente, observou-se que neste processo os catadores são colocados às margens das decisões, pois, mesmo havendo reuniões dos representantes da prefeitura com os catadores, o conhecimento e as opiniões desses eram descartados. Com a chegada do recurso, na opinião dos catadores, deveria se investir na construção do galpão para que tivessem condições de receber a coleta seletiva, porém, os representantes do poder público local decidiram, primeiro, adquirir os caminhos e implantar a coletiva seletiva (VERONESE, 2016; MENESES, 2009).

Devido à baixa produtividade e à dificuldade de escoar os materiais coletados, essa associação tem se limitado a estocar e comercializar individualmente os materiais recicláveis que conseguem acumular: apesar de reconhecerem a importância da rede, não têm condições financeiras de transportar a mercadoria até a sede da rede.

Por sua vez, a associação localizada em Timóteo tem 13 associados e conta com nova sede e caminhão, adquiridos com recursos de projetos junto à Fundação Nacional de Saúde (FUNASA). A nova sede da associação foi construída com este recurso, porém a gestão, o desenvolvimento e controle das obras foram realizados sob a responsabilidade da prefeitura. Na opinião dos catadores, o projeto foi realizado com algumas falhas técnicas, pois, na execução, não foram consideradas algumas particularidades das atividades do catador e, durante o processo, os executores praticamente não dialogaram com os catadores sobre o que poderia impactar nos processos produtivos da associação (MENESES, 2009).

O mais interessante neste grupo é que ele apresenta uma liderança ativa que, de seu ponto de vista, busca (em suas palavras) auxiliar e estimular os catadores em suas atividades e potenciais parcerias (com poder público e outros atores). Porém o foco desses incentivos não é o bem-estar imediato dos catadores, e sim a produtividade, metas e resultados a serem perseguidos na atividade da catação e da produção. Em termos de interação com a rede, por sua vez, ouvimos relatos, não substanciados nem bem explicados, de que houve experiências bem-sucedidas na relação com a sede, o que por sua vez aumenta a resistência tanto de catadores quanto da liderança em cultivar ações coletivas junto à rede.

Finalmente, a associação de João Monlevade, sede da Rede ABC, conta com 26 associados e faz parte do Conselho Municipal de Assistência Social, contando também com algumas parcerias com entidades públicas, privadas e do terceiro setor (MAGNI; GUNTHER, 2014; BARROS; 
PINTO, 2008). Relatam os associados, porém, que as interações com tais parceiros tendem a ser complicadas, pois estes tentam impor ao grupo de catadores uma lógica de produtividade mercadológica pouco atenta aos ideais de associativismo e do próprio MNCR. Por este motivo, dizem os associados, instaurou-se um clima organizacional instável, permeado de sérios problemas de relação interpessoal. Por exemplo, as mulheres catadoras que ali trabalham na triagem relatam ter receio até de ir ao toilette, pois há o risco de serem mal interpretadas por colegas e lideranças que podem ter a impressão de que elas estão "fugindo do trabalho" (SANTOS, 2010; QUIJANO, 2010).

Outra queixa comum é a exaustão que muitos sentem pela obrigação de atingir determinadas metas que Ihes garantiriam uma renda mínima.

Entre as parcerias existentes dessa associação, havia um convênio junto a coletivo que representava uma associação de algumas indústrias de cosméticos para reforma e ampliação da cobertura do galpão e implantação de uma esteira de triagem. Nestes processos, os técnicos, engenheiros e arquitetos, segundo os catadores, não dialogaram com os membros da associação para conhecer suas necessidades e particularidades. Como consequência, na finalização do telhado do galpão, uma catadora questionou a altura, a qual não seria adequada para entrada e movimentação do caminhão de alguns parceiros que doam materiais, o que acarretou revisão do projeto e atraso nas outras. Quanto à esteira, esta foi instalada sem verificar o melhor layout do espaço de triagem, considerando desde a chegada até a prensagem dos materiais que chegarão. Após a implantação, ao iniciarem a utilização da esteira, observaram um crescimento de atividades devido a retrabalhos para adequação, logística interna, entre outros, o que aumentou o tempo do processo de triagem e acumulação de materiais (VERONESE, 2016; MENESES, 2009).

O problema mais comumente relatado, porém, é a falta de comunicação que percebem dentro do empreendimento: não há diálogo entre associados nem entre liderança e associados, e nem com atores externos à associação; o enfoque não está no debate e na deliberação, e sim no produtivismo. Sendo assim, embora esta seja uma associação cuja infraestrutura é considerada referência para outros empreendimentos de catadores e que seja também a sede da Rede $A B C$, o estabelecimento de laços pessoais e comunicação interpessoal - portanto as possibilidades de um associativismo realmente comprometido com a participação dos associados em prol de um bem comum - parece perdido em meio a tais problemas. Sendo assim, talvez não seja surpresa a dificuldade que as demais associações-membro da rede encontram para se inserir numa lógica de redes e associativismo.

\section{CONSIDERAÇÕES FINAIS}

Iniciamos a discussão acima refletindo sobre a noção de Economia Solidária como possível alternativa às lógicas produtivistas e mercadológicas do capitalismo, a emergência e o papel do Movimento Nacional dos Catadores de Materiais Recicláveis, assim como a própria figura do catador e da catadora desses materiais. A essa discussão mais teórica e descritiva, contrapusemos as experiências a nós relatadas, durante a pesquisa que aqui trazemos, de catadores organizados em associações locais, associações estas que fazem parte de uma rede maior de associações e cooperativas de catadores de materiais recicláveis. O que se percebe, nitidamente, é o contraste entre, por um lado, a discussão mais teórica e conceitual sobre o 
potencial emancipatório da dita Economia Solidária e dos tipos de associativismo a ela associados - como é o caso das associações de catadores que estudamos - e, por outro, os reais ganhos e benefícios pessoais, sociais, econômicos e políticos alcançados por catadores reais inseridos em contextos reais.

O que nossos dados demonstram, em resumo, é que ainda há um grande caminho a percorrer por estas formas de associativismo orientadas por lógicas externas ao mercado e ao capital. Um dos problemas vivenciados pelas associações acima e seus associados é exatamente o fato de que, no que tange à construção de parcerias com o poder público, segundo a lógica da Economia Solidária, estas deveriam ser pautadas pelo incentivo à participação democrática dos membros dessas associações na tomada de decisões que lhes dizem respeito, bem como pela possibilidade de eles mesmos deliberarem sobre suas demandas e necessidades; mas, na prática, tal relação com prefeituras e afins segue uma lógica assistencialista e paternalista, que ainda desconsidera por completo as necessidades mais fundamentais dessas pessoas, como a qualidade no ambiente de trabalho. Outra questão, apontada por todos os nossos entrevistados, é que as prefeituras e outros parceiros não seguem as lógicas da autogestão e da cooperação que tais associações prefeririam; em vez delas, priorizam-se lógicas produtivistas e de mercado, como se as associações fossem empresas tradicionais orientadas para metas, lucro e resultados. Em ambos os casos, a própria noção de "solidariedade" desaparece, afetando, inclusive, os modos como os associados interagem entre si: há ruídos e desconfianças, mais do que cooperação e ações solidárias.

Gostaríamos de concluir este trabalho, porém, num tom positivo, chamando atenção para o próprio fato de que, mesmo em meio a tantas forças contrárias, essas pessoas, as catadoras e os catadores, seres marginalizados em todos os sentidos possíveis do termo, vêm cada vez mais se organizando, associando-se, buscando uma forma de participação mais ativa nos rumos de sua própria história. Há um Movimento Nacional que as acolhe e existe há quase vinte anos. Existem hoje cooperativas, associações e redes orientadas para a "catação" espalhadas pelo Brasil, conforme dados do próprio MNCR. E há pessoas que acreditam no potencial deste formato de organização como forma de acesso de tais populações marginalizadas a trabalho, renda e participação democrática.

Neste sentido, pensar o associativismo baseado nos princípios da Economia Solidária pode, sim, apontar-nos caminhos que desafiem o pensamento capitalista, uma vez que este conceito procura caminhar na direção de não sujeitar por completo a produção dos meios de subsistência dos indivíduos às lógicas do capital, ao ser dada maior atenção às relações, aos aspectos domésticos e familiares, aos projetos coletivos, à melhor utilização dos recursos e à consolidação de redes sociais (HESPANHA, 2011). O mero fato de se estar atento a tais questões poderia caminhar na direção de reduzir a fragilidade, precariedade e risco inerentes aos grupos mais marginalizados. Isto, porém, ainda de acordo com Hespanha (2011.), só seria possível a partir da conscientização, por parte de tais populações marginalizadas, acerca de suas possibilidades, desafios e potencialidades enquanto um coletivo, atuando coletivamente para enfrentar as dinâmicas mais opressoras de uma sociedade desigual e capitalista. 


\section{REFERÊNCIAS}

BARROS, V. A.; PINTO, J. B. M. Reciclagem: trabalho e cidadania. In: KEMP, V. H.; CRIVELLARI, H. M. T. (Org.). Catadores na cena urbana: construção de políticas socioambientais. Belo Horizonte: Autêntica, 2008. p. 65-82.

BOLTANSKI, L.; CHIAPELLO, E. O novo espírito do capitalismo. São Paulo: WMF: Martins Fontes, 2009.

BRASIL. Lei 12.305, de 2 de agosto de 2010. Dispõe sobre a Política Nacional de Resíduos Sólidos. Brasília, 2010. Disponível em: http://www.planalto.gov.br/ccivil_03/_ato2007-2010/2010/lei/l12305.htm. Acesso em: jan. 2018.

BUQUE, L. I. B.; RIBEIRO, H. Panorama da coleta seletiva com catadores no município de Maputo, Moçambique: desafios e perspectivas. Saúde e Sociedade, São Paulo, v. 24, n. 1, p. 298-307, 2015.

CUNHA, G. C.; SANTOS, A. M. Economia Solidária e pesquisa em ciências sociais: desafios epistemológicos e metodológicos. In: HESPANHA, P.; SANTOS, A. M. Economia solidária: questões teóricas e epistemológicas. Coimbra, Portugal: Edições Almedina: CES, 2011.

FERNANDES, J. R.; PIRES, A. Metas de produção em cooperativas de recicláveis: tensões entre ambiente cooperativo e atuação competitiva. Interações, Campo Grande, MS, v. 17, n. 2, p. 184-92, abr./jun. 2016.

HARVEY, D. O enigma do capital e as crises do capitalismo. São Paulo: Boitempo, 2011.

HESPANHA, P. Economia solidária de raiz popular: a fase adulta de uma metamorfose? In: HESPANHA, P.; SANTOS, A. M. (Org.). Economia solidária: questões teóricas e epistemológicas. Coimbra, Portugal: Edições Almedina: CES, 2011.

HOBSBAWM, E. J. Mundos do trabalho: novos estudos sobre história operária. Rio de Janeiro: Paz e Terra, 1987.

JACOBI, P. R.; TEIXEIRA, M. A. C. Criação do capital social: o caso ASMARE - Associação dos Catadores de Papel, Papelão e Material Reaproveitável de Belo Horizonte. Cadernos Gestão Pública e Cidadania, São Paulo, v. 2, n. 2, p. 1-51, jun. 1997.

MAGALHÃES, G. H.; ALVES, J. C. M.; VELOSO, L. H. M. CATAVALES e ATLIMARJOM: uma análise das potencialidades do desenvolvimento sustentável local e regional a partir da experiência de uma associação de catadores de materiais recicláveis. Revista Espacios, Caracas, Venezuela, v. 37, n. 32, 2016.

MAGNI, A. A. C.; GUNTHER, W. M. R. Cooperativas de catadores de materiais recicláveis como alternativa à exclusão social e sua relação com a população de rua. Saúde e Sociedade, São Paulo, v. 23, n. 1, p. 14656, 2014.

MENESES, M. P. Justiça Cognitiva. In: CATTANI, A. D. et al. (Org.). Dicionário internacional da outra economia. Coimbra, Portugal: CES: Edições Almedina, 2009.

MNCR. Sobre o Movimento Nacional dos Catadores de Materiais Recicláveis. 2008. Disponível em: http:// www.mncr.org.br/sobre-o-mncr. Acesso em: maio 2018.

POLANYI, K. A grande transformação: as origens de nossa época. Tradução de Fanny Wrabel. 2. ed. Rio de Janeiro: Elsevier, 2012.

QUIJANO, A. Colonialidade do poder e classificação social. In: SANTOS, B. S.; MENESES, M. P. Epistemologia do sul. 2. ed. Coimbra, Portugal: Edições Almedina, 2010. p. 73-117. 
SANTOS, B. S.; HESPANHA, P.; SANTOS, A. M. Apresentação. In: HESPANHA, P.; SANTOS, A. M. Economia solidária: questões teóricas e epistemológicas (Org.). Coimbra, Portugal: Edições Almedina: CES, 2011.

SANTOS, B. S. Para além do pensamento abissal: das linhas globais a uma ecologia de saberes. In: SANTOS, B. S.; MENESES, M. P. Epistemologia do sul (Org.). 2. ed. Coimbra, Portugal: Edições Almedina, 2010. p. $23-71$.

SILVA, R. B. O movimento nacional dos catadores de materiais recicláveis: atores, governação, regulação e questões emergentes no cenário brasileiro. Revista Internacional Interdisciplinar Interthesis, Florianópolis, v. 3. n. 2, p. 1-40, jul./dez. 2006.

VERONESE, M. V. Associativismo entre catadores de material reciclável urbano. Contemporânea, São Carlos, SP, v. 6, n. 1, p. 213-36. jan./jun. 2016.

\section{Sobre os autores:}

Jean Carlos Machado Alves: Doutorando em Sistemas de Gestão Sustentáveis pela Universidade Federal Fluminense (UFF). Mestre em Engenharia de Produção pela Universidade Federal de Santa Maria (UFSM). Especialista em Gestão Ambiental e Social (MBA/UFSJ). Graduado em Administração pela Universidade Federal de São João del-Rei (UFSJ). Realizou estágio doutoral no Centro de Estudos Sociais na Universidade de Coimbra, em Portugal, através do Programa de Doutorado Sanduíche da Capes 2017/2018. Professor do departamento de Engenharia de Produção da Universidade Federal de Ouro Preto, campus João Monlevade; professor orientador do Laboratório de Economia Solidária - Incubadora de Empreendimentos Sociais e Solidários da UFOP-INCOP. Tem experiência na área de Administração e Produção, pesquisando, principalmente, os seguintes temas: Gestão Socioambiental, Engenharia da Sustentabilidade, Economia Solidária, Terceiro Setor, Redes, Empreendedorismo, Produção e Qualidade. E-mail: jean.mep@gmail.com, Orcid: http://orcid.org/0000-0001-6216-8165

Letícia Helena Medeiros Veloso: Doutora e mestre em Antropologia pela University of Chicago. Graduada em Comunicação Social pela Pontifícia Universidade Católica do Rio de Janeiro (PUCRJ). Professora adjunta do Departamento de Sociologia e do Programa de Pós-Graduação em Sociologia e Direito da Universidade Federal Fluminense (UFF). Atua principalmente nas seguintes áreas: Antropologia e Sociologia Urbana; Antropologia e Sociologia Política; Antropologia e Sociologia das Emoções; e Marcadores Sociais da Diferença. E-mail: Iveloso.uff@gmail.com, Orcid: http://orcid.org/0000-0001-5382-8926

Emmanuel Paiva de Andrade: Doutor, mestre e graduado em Engenharia de Produção pela Universidade Federal do Rio de Janeiro (UFRJ). Atua desde 1992 na Universidade Federal Fluminense em Niterói, onde foi coordenador de curso, chefe de departamento, diretor da Escola de Engenharia, pró-reitor de Planejamento e vice-reitor. Foi fundador, em 1998, do Núcleo de Estudos em Inovação, Conhecimento e Trabalho (NEICT), do qual é diretor atualmente, atuando ainda no ensino de graduação e pós-graduação, em áreas como Gestão da Inovação, Gestão do Conhecimento e Planejamento Estratégico. E-mail: emmanueluff@gmail.com, Orcid: http://orcid.org/0000-0002-2173-3110

Andreia Maria da Silva: Mestre em Sistemas de Gestão na Universidade Federal Fluminense (UFF). Possui MBA em Gestão de Negócios e Inteligência Competitiva pela Universidade Federal 
do Estado do Rio de Janeiro (UNIRIO). Graduada em Ciências Contábeis e em Administração de Empresas pela Faculdade de Ciências Contábeis e Administrativas Moraes Júnior; graduada em Design de Interiores pela Universidade Veiga de Almeida (UVA). Analista em Ciência e Tecnologia da Comissão Nacional de Energia Nuclear/Instituto de Engenharia Nuclear (CNEN/ IEN) e pesquisadora integrante do Projeto de Pesquisa "Gestão do Conhecimento em Ciências Nucleares". Integra o Grupo de Pesquisa do IBCT "BRIET: Biblioteconomia, Recuperação de Informação, E-Science e Suas Teorias". É também pesquisadora do Grupo de Pesquisa em Conhecimento, Pessoas e Inovação (Gecopi), que é um desdobramento do Núcleo de Estudos em Inovação, Conhecimento e Trabalho (NEICT) da UFF. E-mail: amsilva02@uol.com.br, Orcid: http://orcid.org/0000-0002-2526-186X 